\title{
EFEITO DO INIBIDOR DE PROTEASE KUNITZ SOBRE NÍVEIS DE LIPOXIGENASES EM SEMENTES DE SOJA
}

\author{
Effect of protease inhibitor on the levels of lipoxygenase in soybean seeds \\ Josie Gomes de Almeida Barros', Rita Maria Alves de Moraes², Newton Deniz Piovesan ${ }^{3}$, \\ Everaldo Gonçalves de Barros ${ }^{4}$, Maurilio Alves Moreira ${ }^{5}$
}

\begin{abstract}
RESUMO
As lipoxigenases (LOX) são responsáveis pelo “beany flavor”, sabor característico da soja [Glycine max. (L.) Merrill], que é o maior obstáculo ao consumo da soja nos países ocidentais. O inibidor de tripsina Kunitz (KTI) é responsável por $80 \%$ da inibição da atividade tríptica, além de provocar hiperplasia pancreática em animais monogástricos. Essas duas características são muito importantes em programas de melhoramento que visam à melhoria da qualidade da soja. Objetivou-se, neste trabalho verificar o efeito do inibidor de protease (KTI), sobre níveis de LOX em sementes de soja, nos seguintes genótipos: KTI+/LOX+, KTI+/LOX-, KTI/LOX+ e KTI-/LOX-. As LOXs foram identificadas por teste colorimétrico, atividade enzimática e eletroforese em gel de poliacrilamida. O teor de proteína foi quantificado pelo método do ácido bicinconínico para determinação da atividade específica de LOX. Observouse que, para o genótipo KTI+/LOX+, a atividade específica de LOX 1 foi alta, variando de 177,92 a 206,94 UA/mg de proteína e para LOX 3 variou de 17,90 a 19,85 UA/mg de proteína; para KTI+/LOX- e KTI-/LOX- não foi detectada atividade de LOX e que para o genótipo KTI-/LOX+ a atividade específica para LOX 1 variou de 117,24 a 124,64 UA/mg de proteína, e de 17,35 a 20,29 UA/mg de proteína para LOX 3. Houve uma redução de $40 \%$ na atividade específica de LOX1 e de $1 \%$ para LOX 3, no genótipo KTI-/LOX+, quando comparados ao KTI+/LOX+. Esses resultados comprovam uma associação negativa entre o inibidor de tripsina Kunitz e a atividade de lipoxigenases.
\end{abstract}

Termos para indexação: Glycine max, tripsina, proteína, atividade enzimática, KTI.

\section{ABSTRACT}

Lipoxygenases (LOX) are responsible for the beany flavor, which is the most important obstacle for the consumption of soybean [Glycine max. (L.) Merrill] products in Western countries. The Kunitz trypsin inhibitor (KTI) is responsible for $80 \%$ of the inhibition of tryptic activity in soybean seeds, and besides it can cause pancreatic hyperplasia in monogastric animals. These two traits are very important in soybean breeding programs that aim the improvement of soy protein quality. The objective of this study was to verify the influence of KTI on LOX levels in soybean seeds by analyzing the following genotypes: KTI+/LOX+, KTI+/LOX-, KTI-/ LOX+ and KTI-/LOX-. LOX 1 and LOX 3 were identified by colorimetric, activity and electrophoretic assays. Protein content was determined by the bicinchoninic method for determination of LOX specific activity. For genotype KTI+/LOX+, LOX 1 specific activity was high varying from 177.92 to $206.94 \mathrm{AU} / \mathrm{mg}$ of protein and LOX 3 activity varied from 17.90 to $19.85 \mathrm{AU} / \mathrm{mg}$ of protein. No LOX activity was detected in genotypes KTI+/LOX- and KTI-/LOX-. For genotype KTI-/LOX+, LOX 1 activity varied from 117.24 to 124.64 AU/mg of protein, and the activity of LOX 3 from 17.35 to $20.29 \mathrm{AU} / \mathrm{mg}$ of protein. There was a reduction of $40 \%$ on LOX 1 specific activity and $1 \%$ for LOX 3 in the KTI-/LOX+ genotype in comparison to genotype KTI+/LOX+. These results indicate an inverse relationship between the presence of the Kunitz trypsin inhibitor in soybean seeds and lipoxygenase activity.

Index terms: Glycine max, trypsin, protein, enzymatic activity, KTI.

(Recebido em 22 de novembro de 2005 e aprovado em 21 de março de 2007)

\section{INTRODUÇÃO}

A utilização da soja, [Glycine max. (L.) Merrill], na alimentação dos brasileiros ainda é bem restrita. Seu uso destina-se, em grande parte, à produção de ração animal e à obtenção de óleos e derivados (gordura hidrogenada e margarina) que têm sido bem aceitos pelo consumidor (RACKIS et al., 1979). Os fatores que afetam o consumo de soja e derivados nos países ocidentais são, principalmente, o seu sabor característico, denominado "beany flavor" (RACKIS et al., 1979), e a presença de inibidores de proteases, que constituem um dos principais fatores

\footnotetext{
Mestre - Instituto de Biotecnologia Aplicada a Agropecuária/BIAGRO - Universidade Federal de Viçosa/UFV - 36570-000 - Viçosa, MG josieflower2000@yahoo.com.br

Engenheira Agrônoma, Doutora - Naturalle Agro Mercantil Ltda -Av. Dr. Jaime Ribeiro Luz, 971, sl 34 - 38408-188 - Uberlândia, MG - rita@naturalle.com ${ }^{3}$ Mestre - Instituto de Biotecnologia Aplicada a Agropecuária/BIAGRO - Universidade Federal de Viçosa/UFV - 36570-000 - Viçosa, MG - piovesan@ufv.br ${ }^{4}$ Ph.D, Professor Titular - Instituto de Biotecnologia Aplicada a Agropecuária/BIAGRO - Universidade Federal de Viçosa/UFV - 36570-000 - Viçosa, MG ebarros@ufv.br

${ }^{5} \mathrm{Ph} . \mathrm{D}$, Professor Titular - Instituto de Biotecnologia Aplicada a Agropecuária/BIAGRO - Universidade Federal de Viçosa/UFV - $36570-000$ - Viçosa, MG moreira@ufv.br
} 
antinutricionais da soja (ANDERSON-HAFERMANN et al., 1992). Contudo, a recente alegação de saúde e propriedades nutricionais do consumo de soja e de seus derivados têm promovido um aumento de produtos à base de soja e uma melhoria no processamento e obtenção de produtos de melhor sabor para o consumo ocidental (MESSINA, 2002).

Enzimas lipoxigenases estão presentes em semente de soja na forma de três isoenzimas: LOX 1, LOX 2 e LOX 3. Elas são codificadas por três genes dominantes, os quais são herdados de modo mendeliano. O locos para LOX 1 e LOX 2 estão mapeados no mesmo grupo de ligação e o locos para LOX 3 é independente (KITAMURA et al., 1983). As massas moleculares das LOXs são, respectivamente, 94.038, 97.035 e 96.541 Da (GALLIARD \& CHAN, 1980).

Em plantas, as LOXs têm uma função geral de síntese de hidroperóxidos de ácidos graxos poliinsaturados, que atuariam como intermediários-chaves para um número de rotas metabólicas divergentes. Dessa forma, a rota das LOXs, em plantas, poderia ser similar à rota das LOXs e cicloxigenases de animais, onde o hidroperóxido ou endoperóxido formado por essas enzimas são transformados em leucotrienos, prostaglandinas, prostaciclinas e tromboxanos, dependendo da natureza do estímulo celular. Esses metabólitos demonstram uma poderosa atividade reguladora em mamíferos (SAMUELSSON et al., 1987; SCHEWE et al., 1986).

Os inibidores de protease representam cerca de $6 \%$ das proteínas presentes nos grãos de soja (BRANDON et al., 1993). O uso de produtos derivados de soja que contêm esses inibidores ativos em cobaias, por tempo prolongado, promove o desenvolvimento de hiperplasia nodular pancreática (aumento do número de células) e adenomas celulares (tumor benigno) (BRANDON et al., 1989). Os inibidores de protease, em grãos de soja, são representados pelo inibidor de tripsina Kunitz (KTI) e pelo inibidor de tripsina e quimotripsina Bowman-Birk (BBI) (STAHLHUT \& HYMOWITZ, 1983). Cerca de $80 \%$ da inibição da atividade tríptica em semente de soja é causada pela ação do KTI (BRANDON et al., 1987).

Apesar de se fazer tratamento térmico para eliminar a atividade dos inibidores de proteases em produtos de soja, esses ainda conservam cerca de $10-20 \%$ da atividade de inibição de tripsina. Essa atividade residual é devida ao KTI, que tem maior resistência ao aquecimento (JIAO et al., 1992). A eliminação genética de KTI por meio de cruzamentos, com linhagens que contenham genes para sua ausência, é uma alternativa para a supressão desse fator antinutricional em variedades comerciais de soja. Monteiro et al. $(2003,2004)$ avaliaram a qualidade protéica de farinhas de soja que diferiam com relação à presença de lipoxigenases e/ou inibidor de tripsina Kunitz. Esses autores concluíram que a ausência do inibidor melhora, significativamente, a digestibilidade da proteína de soja em ensaios de digestibilidade in vivo, eliminando-se a necessidade de se empregar elevadas temperaturas nos produtos.

A atividade das enzimas lipoxigenases e do inibidor de tripsina é variável com a cultivar e com o local de cultivo. Temperaturas mais amenas apresentam um maior valor de atividade de LOX 1 e LOX 2+3 (KUMAR et al., 2003).

No Programa de Melhoramento de Soja para a Agroindústria, em desenvolvimento no BIOAGRO, na Universidade Federal de Viçosa, estão sendo desenvolvidas, por meio de retrocruzamentos, linhagens que apresentam ausência de LOX e KTI, visando à melhoria da qualidade nutricional e do sabor da soja. Dessa forma objetivou-se, aqui, avaliar a influência do inibidor de tripsina Kunitz sobre a atividade das enzimas lipoxigenases.

\section{MATERIAL E MÉTODOS}

\section{Material Genético}

Sementes de soja de linhagens derivadas da variedade comercial Spring foram usadas para determinar o efeito da eliminação genética do KTI sobre a atividade de LOXs. Os genótipos possuíam as seguintes combinações: KTI+/LOX+, KTI+/LOX-, KTI-/LOX+ e KTI/LOX-.

\section{Teste colorimétrico para detecção de LOX}

Foram utilizados testes colorimétricos nãodestrutivos para a identificação de LOX 1 e LOX 3, segundo a metodologia proposta por Suda et al. (1995), com modificações, tomando-se uma pequena porção do cotilédone das sementes, do lado oposto ao eixo embrionário, para a confirmação de indivíduos com presença/ausência de lipoxigenases. A identificação de LOX 2, apesar de ser possível, não foi efetuada devido ao alelo dominante de LOX 2 estar estreitamente ligado ao alelo dominante de LOX 1. Portanto ao se identificar a presença de LOX 1 está se identificando, também, a presença de LOX 2.

\section{Análise eletroforética de LOX e KTI}

LOX e KTI foram identificados por eletroforese em amostras de $10 \mathrm{mg}$ de semente, retiradas da região do cotilédone, do lado oposto ao eixo embrionário, de um total de 10 sementes de cada genótipo: genótipos 1 (LOX/KTI-), 2 (LOX+/KTI+), 3 (LOX+/KTI-) e 4 (LOX-/KTI+). 
(a) Para as análises de LOXs, as amostras foram extraídas com $0,6 \mathrm{~mL}$ de tampão Tris- $\mathrm{HCl} 0,5 \mathrm{M}$, pH 6,8 e o extrato obtido foi centrifugado a $15.700 \mathrm{~g}$ por 20 minutos, à temperatura ambiente. Em seguida, os extratos foram aplicados em géis de poliacrilamida contendo SDS, com base no sistema descontínuo descrito por Laemmli (1970). (b) Para as análises de KTI, as amostras foram extraídas com 0,6 mL de tampão Tris- $\mathrm{HCl} 50 \mathrm{mM}, \mathrm{pH} 8,2, \mathrm{CaCl}_{2} 10$ $\mathrm{mM}$ e o extrato obtido foi centrifugado a $15.700 \mathrm{~g}$ por 20 minutos, à temperatura ambiente. A separação das proteínas dos extratos em gel de poliacrilamida $14 \%$ foi realizada conforme o sistema descontínuo proposto por Laemmli (1970). A coloração dos géis foi realizada com o corante Coomassie Blue.

\section{Análise da atividade de LOX}

Para a atividade de LOX, as amostras foram maceradas com 0,6 mL de tampão Tris- $\mathrm{HCl} 60 \mathrm{mM}, \mathrm{CaCl}_{2}$ $15 \mathrm{mM}$, sacarose $13 \%, \mathrm{pH} 8,2$. Os extratos obtidos foram centrifugados a $15.700 \mathrm{~g}$ por 15 minutos, à $4^{\circ} \mathrm{C}$.

A determinação das atividades de LOX 1 e 3 foi realizada conforme descrito por Oliveira et al. (1998). Para a atividade de LOX 1, 2,5 mL do extrato da semente foi adicionado a uma mistura contendo $1 \mathrm{~mL}$ de tampão borato de sódio 0,1 M, pH 9,5 e $6 \mathrm{~mL}$ de linoleato de sódio $10 \mathrm{mM}$. A absorbância da solução foi determinada em espectrofotômetro em $234 \mathrm{~nm}$, medida após 2 min de reação. Para a atividade de LOX 3,15 mL do extrato da semente foi adicionado a uma mistura contendo $1 \mathrm{~mL}$ de tampão fosfato de sódio $0,1 \mathrm{M}, \mathrm{pH}$ 6,8 e $35 \mathrm{~mL}$ de linoleato de sódio 10 mM. A absorbância da solução foi determinada em $280 \mathrm{~nm}$, medida após 2 min de reação.

\section{Quantificação de proteína}

O teor de proteína dos extratos das análises de atividade de LOX foi determinado pelo método do ácido bicinconínico, segundo metodologia descrita por Smith et al. (1985). As amostras foram diluídas 20 vezes e $100 \mathrm{~mL}$ de cada foi aplicada em placa de ELISA em triplicata. Foram aplicados às amostras $200 \mathrm{~mL}$ do reagente contendo ácido bicinconínico e $\mathrm{CuSO}_{4}$ na proporção de 50:1. Para acelerar a reação a placa foi submetida a banho-maria a $37^{\circ} \mathrm{C}$, por 30 min. Em seguida, a placa foi retirada do banho-maria, permanecendo por $20 \mathrm{~min}$, para que as amostras atingissem a temperatura ambiente. Posteriormente, foi feita a leitura da placa em espectofotômetro utilizando um filtro de 560 nm. Uma curva padrão foi preparada utilizando-se solução de albumina sérica bovina (BSA) $0,1 \%$. Para isso, foram utilizadas $8,10,15$ e $20 \mathrm{mg}$ de BSA em triplicata. A quantidade de proteína dos extratos foram calculadas utilizando-se a equação derivada da curva padrão. Os níveis relativos de proteína, nos extratos das sementes, foram determinadas considerando a média das triplicatas.

\section{Determinação da atividade específica de LOX}

A atividade específica foi determinada relacionando-se o valor encontrado na reação de LOX, como Unidade de Absorvância, com a quantidade total de proteínas, de acordo com a seguinte equação:

$$
\text { Atividade Específica }=\frac{\text { unidade de absorvância }}{\text { mg de proteínas }}
$$

Onde, $\mathrm{UA}=\mathrm{Abs} * \mathrm{FD}$

e:

Abs = Absorbância em 234 ou $280 \mathrm{~nm}$

FD = fator de diluição da amostra

Foram processadas análises de variância das atividades específicas de LOX 1 e LOX 3 utilizando-se o aplicativo computacional GENES (CRUZ, 1997). As médias das atividades específicas foram comparadas pelo teste de Tukey a 5\% de probabilidade.

\section{RESULTADOS E DISCUSSÃO}

Este é um trabalho pioneiro na avaliação do efeito da ausência do inibidor de protease Kunitz (KTI) sobre os níveis de lipoxigenases, em semente de soja. Um outro trabalho mostrou o inverso, ou seja, o efeito de lipoxigenases sobre níveis do inibidor de protease KTI e BBI (CARVALHO et al., 1999).

Segundo Carvalho et al. (1999), a eliminação genética de LOX de semente provocou redução da inibição da atividade de tripsina e de quimotripsina pelos inibidores KTI e BBI, presentes no grão. Essa redução só foi verificada com a eliminação das três LOXs encontradas em sementes de soja, devendo-se ressaltar que a presença de qualquer uma delas restaurou o nível de atividade inibitória dos inibidores de proteases.

$\mathrm{Na}$ Figura 1 está representado um gel de poliacrilamida $9 \%$ para identificação de LOX, não sendo possível discriminar as LOXs (LOX 1, 2 e 3). Foram aplicadas nas canaletas $25 \mu \mathrm{L}$ de extrato bruto. Pode-se verificar que a intensidade da banda de LOX foi supostamente reduzida no genótipo KTI-/LOX+ (canaletas 5 e 6), em comparação com o genótipo KTI+/LOX+ (canaletas 1 e 2) indicando que, na ausência do KTI a expressão das LOXs foi reduzida. Na Figura 2 está representado um gel de poliacrilamida $14 \%$ para identificação do KTI. Nesse gel, pode-se também identificar a banda correspondente a LOX. 


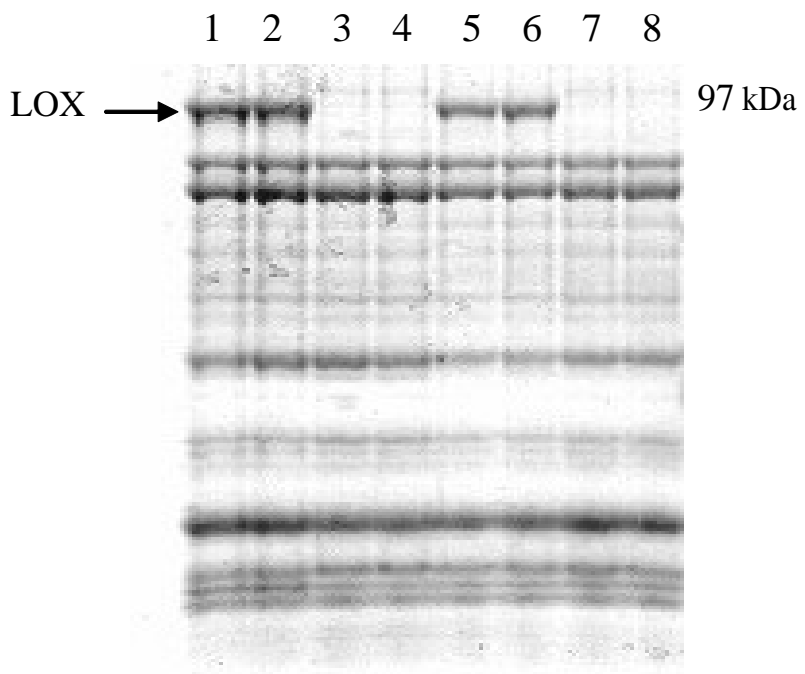

Figura 1 - Gel de poliacrilamida $9 \%$ para identificação das LOX. A banda correspondente às LOXs está indicada com uma seta. As amostras 1 e 2 representam o genótipo KTI+/LOX+, 3 e 4 KTI-/LOX+, 5 e 6 KTI-/LOX+ e 7 e 8 KTI-/LOX-.

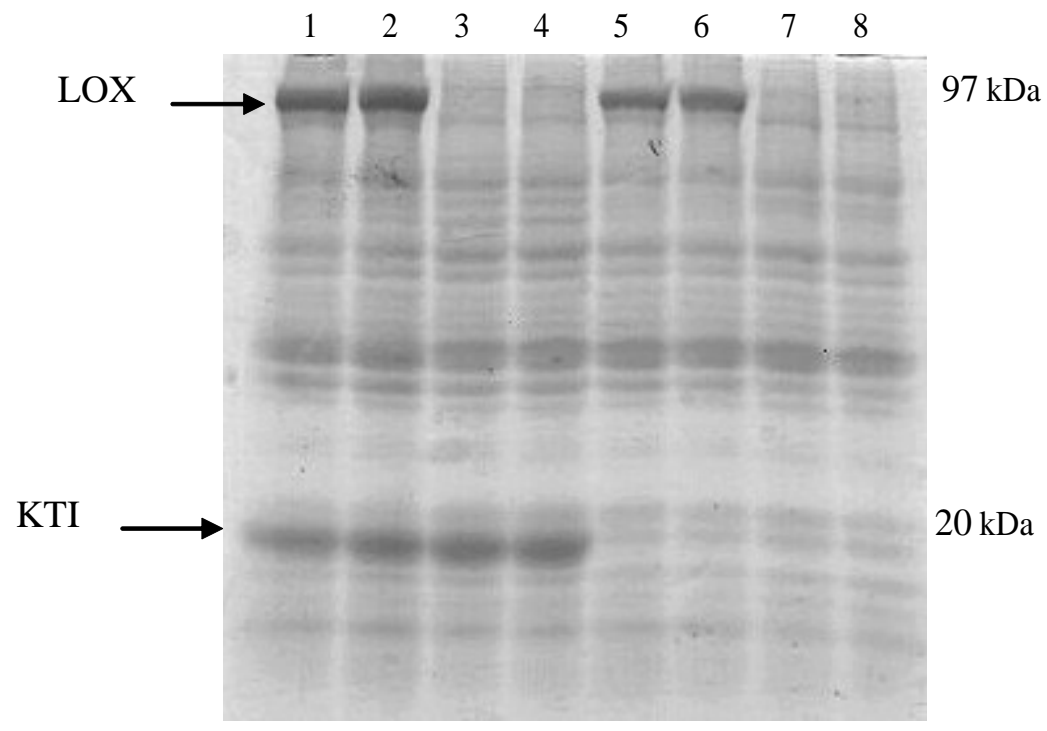

Figura 2 - Gel de poliacrilamida 14\% para identificação de LOX e KTI. As amostras 1 e 2 representam o genótipo KTI+/ LOX+, 3 e 4 KTI-/LOX+, 5 e 6 KTI-/LOX+ e 7 e 8 KTI-/LOX-.

Na Tabela 1 estão representados as atividades específicas de LOX 1 e LOX 3 obtidas em três amostras dos genótipos 1 (LOX-/KTI-), 2 (LOX+/KTI+), 3 (LOX+/ KTI-) e 4 (LOX-/KTI+). É constatado que existe uma grande variação na atividade de LOX 1 e uma pequena variação na atividade de LOX 3 quando na ausência do KTI.

Nas Figuras 3 e 4 são apresentadas, em forma de gráfico, as médias dos valores das atividades específicas de LOX 1 e 3 nos diferentes genótipos, mostrando mais uma vez a grande variação da atividade específica de LOX 1 quando na ausência de KTI, genótipos 2 e 3 (Figura 3) e pequena diferença na atividade específica de LOX 3 entre os genótipos 2 e 3 (Figura 4).

A redução na atividade específica foi de $40 \%$ para LOX 1 e de apenas $1 \%$ para LOX 3 no genótipo 3 (LOX+/ KTI-) em comparação com o genótipo 2 (LOX+/KTI+). A redução da atividade específica de LOX quando o KTI está ausente sugere uma relação entre essas duas 
Tabela 1 - Valores médios da atividade específica (UA/mg de proteína) de LOX 1 e 3 em quatro genótipos de sementes de soja.

\begin{tabular}{ccc}
\hline Genótipo & $\begin{array}{c}\text { Atividade Específica LOX 1 } \\
\left(\mathrm{UA}_{234 \mathrm{~nm}} / \text { mg Proteína }\right)^{2}\end{array}$ & $\begin{array}{c}\text { Atividade Específica LOX 3 } \\
\text { (UA }_{280 \mathrm{~nm}} / \mathrm{mg}_{\text {Proteína })}\end{array}$ \\
\hline 1- LOX-/KTI- & $12,02 \pm 0,91$ & $4,43 \pm 0,55$ \\
2- LOX+/KTI+ & $200,75 \pm 20,45$ & $18,97 \pm 0,99$ \\
3- LOX+/KTI- & $120,92 \pm 3,70$ & $18,84 \pm 1,47$ \\
4- LOX-/KTI+ & $9,52 \pm 0,21$ & $3,66 \pm 0,26$ \\
\hline
\end{tabular}

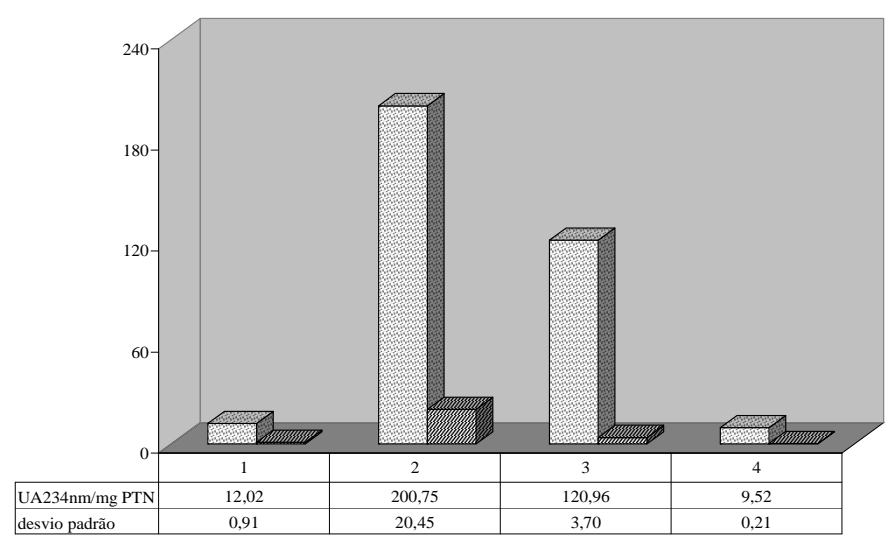

Figura 3 - Média das atividades específicas de LOX 1 nos quatro genótipos em sementes de soja. Amostra 1 LOX-/ KTI-, amostra 2 LOX+/KTI+, amostra 3 LOX+/ KTI- e amostra 4 LOX-/KTI+.

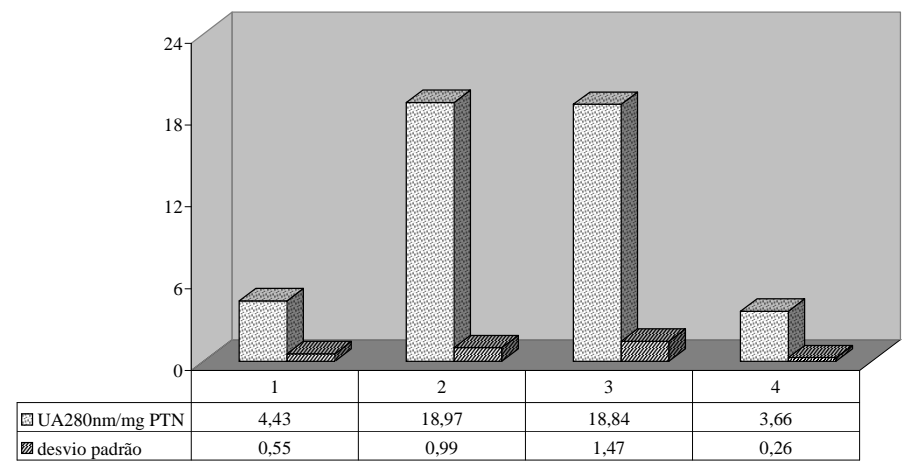

Figura 4 - Média das atividades específicas de LOX 3 nos quatro genótipos em sementes de soja. Amostra 1 LOX-/ KTI-, amostra 2 LOX+/KTI+, amostra 3 LOX+/ KTI- e amostra 4 LOX-/KTI+.

características. Nos genótipos 1 (LOX-/KTI-) e 4 (LOX-/ $\mathrm{KTI}+$ ) onde a LOX não estava presente, a atividade específica dessa enzima foi baixa sendo considerada nula. Silva et al. (2004) mostraram que plantas de soja, variando para LOXs em suas sementes, quando sob ataque de mosca branca aumentaram seus níveis de inibidores de protease, em folhas, mantendo inalterado o nível da atividade de LOXs nas folhas. Esses autores concluíram que a produção de inibidores de protease está envolvida no mecanismo de defesa da soja ao ataque da mosca branca.

Os resultados obtidos pelo teste Tukey (Tabela 2) confirmam o efeito da ausência do KTI na redução da atividade de LOX 1 (genótipos 2 e 3). Essa redução na atividade só foi significativa para $\operatorname{LOX} 1$, sendo não significativa para LOX 3. 
Tabela 2 - Comparação dos valores médios das atividades específicas de LOX 1 e LOX 3.

\begin{tabular}{ccc}
\hline Genótipo & LOX 1 & LOX 3 \\
\hline 1- LOX- / KTI- & $12,02 \mathrm{c}$ & $4,43 \mathrm{a}$ \\
2- LOX+ / KTI+ & $200,75 \mathrm{a}$ & $18,97 \mathrm{a}$ \\
3- LOX+ / KTI- & $120,96 \mathrm{~b}$ & $18,84 \mathrm{a}$ \\
4- LOX- / KTI+ & $9,52 \mathrm{c}$ & $3,67 \mathrm{a}$ \\
\hline
\end{tabular}

Médias seguidas pela mesma letra não diferem entre si pelo teste de Tukey, a 5\% de probabilidade.

Uma hipótese a ser testada com o resultado desse trabalho é que existe um nível de controle da expressão das LOXs que pode ser regulada pelo inibidor de protease. O próximo passo é avaliar o nível de expressão da proteína utilizando técnicas mais refinadas e que quantifiquem a expressão das proteínas.

\section{CONCLUSÃO}

Os resultados obtidos no presente estudo comprovam que existe uma associação entre o inibidor de protease Kunitz e as lipoxigenases, ou seja, na ausência do KTI o nível de LOX 1 foi reduzido, o que foi demonstrado por meio da atividade da enzima e por eletroforese em gel de poliacrilamida. O nível de LOX 3 não foi reduzido significativamente.

\section{REFERÊNCIAS BIBLIOGRÁFICAS}

ANDERSON-HAFERMANN, J. C.; ZHANG, Y.; PARSONS, C. M. Effect of heating on nutritional quality of conventional and kunitz trypsin inhibitor-free soybeans. Poultry Science, London, v. 71, p. 1700-1709, 1992.

BRANDON, D. L.; BATES, A. H.; FRIEDMAN, M. Monoclonal antibody-based enzyme immunoassay of the bowman-birk protease inhibitor of soybean. Journal Agricultural and Food Chemistry, Easton, v. 37, n. 4, p. 1192-1196, 1989.

BRANDON, D. L.; BATES, A. H.; FRIEDMAN, M. Antigenicity of soybean protease inhibitors. In: TROLL, W.; KENNEDY, A. R. (Eds.). Proteinase inhibitors as cancer chemopreventive agents. New York: Plenum, 1993. p. $107-129$.

BRANDON, D. L.; HAQUE, S.; FRIEDMAN, M. Interaction of monoclonal antibodies with soybean trypsin inhibitors. Journal Agricultural and Food Chemistry, Easton, v. 35, p. 195-200, 1987.

CARVALHO, W. L.; OLIVEIRA, M. G. A.; BARROS, E. G.; MOREIRA, M. A. Lipoxygenases affect protease inhibitor levels in soybean seeds. Plant Physiology Biochemistry, [S.1.], v. 37, p. 497-501, 1999.

CRUZ, C. D. Programa genes: aplicativo computacional em genética e estatística. Viçosa: UFV, 1997. 442 p.

GALLIARD, T.; CHAN, H. W. S. Lipoxygenases in the biochemistry of plants, P.K. New York: Academic, 1980. v. 4.

JIAO, J.; YEE, B. C.; KOBREHEL, K.; BUCHANAN, B. B. Effect of thioredoxin-linked reduction on the activity and stability of the Kunitz and bowman-birk soybean trypsin inhibitor proteins. Journal Agricultural and Food Chemistry, Easton, v. 40, n. 12, p. 2333-2336, 1992.

KITAMURA, K.; DAVIES, C. S.; KAIZUMA, N. Genetic analysis of a null-allele for lipoxygenase-3 in soybean seeds. Crop Science, Madison, v. 23, n. 5, p. 924-927, 1983.

KUMAR, V.; RANI, A.; TINDWANI, C.; JAIN, M. Lipoxygenase isozymes and trypsin inhibitor activities in soybean as influenced by growing location. Food Chemistry, London, v. 83, p. 79-83, 2003.

LAEMMLI, U. K. Cleavage of structural proteins during the assembly of the head of bacteriophage T4. Nature, London, v. 277, p. 680-685, 1970.

MESSINA, J. M. Soyfoods and soybean isoflavones and menopausal health. Nutrition Clinical Care, [S.1.], v. 5, n. 6, p. 272-282, 2002.

MONTEIRO, M. R. P.; COSTA, N. M. B.; OLIVEIRA, M. G. A.; PIRES, C. V.; MOREIRA, M. A. Qualidade protéica de linhagens de soja com ausência do inibidor de tripsina e das isoenzimas lipoxigenases. Revista de Nutrição, Campinas, v. 17, n. 2, p. 195-205, 2004.

MONTEIRO, M. R. P.; MOREIRA, M. A.; COSTA, N. M. B.; OLIVEIRA, M. G. A.; PIRES, C. V. Avaliação da digestibilidade protéica de genótipos de soja com ausência e presença do inibidor de tripsina kunitz e lipoxigenases. Brazilian Food Technology, São Paulo, v. 6, n. 1, p. 99-107, 2003. 
OLIVEIRA, D. A.; PIOVESAN, N. D.; MORAES, R. M. A.; ROCHEBOIS, G. B.; OLIVEIRA, M. G. A.; BARROS, E. G.; MOREIRA, M. A. Identification of the three genotypic classes for soybean lipoxygenases 1 and 3 based on enzymatic activity. Biotechnology Techniques, [S.1.], v. 12, n. 1, p. 71-74, 1998.

RACKIS, J. J.; SESSA, D. J.; HONIG, D. H. Flavor problems of vegetable food proteins. Journal American Oil Chemistry Society, Chicago, v. 56, p. 262-271, 1979.

SAMUELSSON, B.; DAHLEN, S. E.; LINDGREN, J. A.; ROUZER, C. A.; SERHAN, C. N. Leucotrienes and lipoxins: structures, biosynthesis, and biological effects. Science, London, v. 237, p. 1171-1176, 1987.

SCHEWE, T.; RAPOPORT, S. M.; KUHN, H. Enzymology and physiology of reticulocyte lipoxygenase: comparison with others lipoxygenases. Advances Enzymology Related Areas Molecular Biology, [S.1.], v. 58, p. 191272, 1986.
SILVA, F. B.; OLIVEIRA, M. G. A.; BRUMANO, M. H. N.; PIRES, C. V.; ALMEIDA, F. T.; OLIVEIRA, J. A.; PILON, A. M.; SILVA, C. H. O.; MOREIRA, M. A. Função bioquímica da via das lipoxigenases em plantas de soja submetidas ao ataque de mosca-branca (Bemisia argentifolli). Ciência e Agrotecnologia, Lavras, v. 28, n. 2, p. 406-413, 2004.

SMITH, P. K.; KROHN, R. I.; HERMANSON, G. T.; MALLIA, A. K.; GARTNER, F. H.; PROVENZANO, M. D.; FUJIMOTO, E. K.; GOEKE, M. M.; OLSON, B. J.; KLENK, D. C. Measurement of protein using bicinchoninic acid. Anaytical Biochemistry, New York, v. 15, p. 76-85, 1985.

STAHLHUT, R. W.; HYMOWITZ, T. Variation in the low molecular weight proteinase inhibitors of soybeans. Crop Science, Madison, v. 23, p. 766-769, 1983.

SUDA, I.; HAJIKA, M.; NISHIBA, Y. Simple and rapid method for the selective detection of individual lipoxygenase isozymes in soybean seeds. Agriculture Food Chemistry, Easton, v. 43, p. 742-747, 1995. 